\title{
Comparison of La3+ and mixed rare earths-loaded magnetic chitosan beads for
} fluoride adsorption

\section{Liang, Peng; An, Ruiqi; Li, Ruifen; Wang, Dongfeng}

Published in:

International Journal of Biological Macromolecules

Link to article, DOI:

10.1016/j.ijbiomac.2017.12.151

Publication date:

2018

Document Version

Peer reviewed version

Link back to DTU Orbit

Citation (APA):

Liang, P., An, R., Li, R., \& Wang, D. (2018). Comparison of La3+ and mixed rare earths-loaded magnetic chitosan beads for fluoride adsorption. International Journal of Biological Macromolecules, 111, $255-263$. https://doi.org/10.1016/j.ijbiomac.2017.12.151

\section{General rights}

Copyright and moral rights for the publications made accessible in the public portal are retained by the authors and/or other copyright owners and it is a condition of accessing publications that users recognise and abide by the legal requirements associated with these rights.

- Users may download and print one copy of any publication from the public portal for the purpose of private study or research.

- You may not further distribute the material or use it for any profit-making activity or commercial gain

- You may freely distribute the URL identifying the publication in the public portal 


\section{Accepted Manuscript}

Comparison of $\mathrm{La} 3+$ and mixed rare earths-loaded magnetic chitosan beads for fluoride adsorption

Peng Liang, Ruiqi An, Ruifen Li, Dongfeng Wang

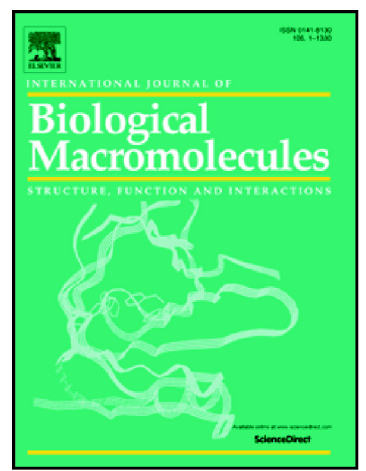

PII: S0141-8130(17)32364-4

DOI: https://doi.org/10.1016/j.ijbiomac.2017.12.151

Reference:

BIOMAC 8813

To appear in:

Received date: $\quad 29$ June 2017

Revised date: $\quad 8$ October 2017

Accepted date: $\quad 28$ December 2017

Please cite this article as: Peng Liang, Ruiqi An, Ruifen Li, Dongfeng Wang, Comparison of $\mathrm{La} 3+$ and mixed rare earths-loaded magnetic chitosan beads for fluoride adsorption. The address for the corresponding author was captured as affiliation for all authors. Please check if appropriate. Biomac(2017), https://doi.org/10.1016/j.ijbiomac.2017.12.151

This is a PDF file of an unedited manuscript that has been accepted for publication. As a service to our customers we are providing this early version of the manuscript. The manuscript will undergo copyediting, typesetting, and review of the resulting proof before it is published in its final form. Please note that during the production process errors may be discovered which could affect the content, and all legal disclaimers that apply to the journal pertain. 
Comparison of $\mathrm{La}^{3+}$ and mixed rare earths-loaded magnetic chitosan beads for

\section{fluoride adsorption}

Peng Liang ${ }^{\mathrm{a}^{*}}$, Ruiqi An ${ }^{\mathrm{a}^{*}}$, Ruifen $\mathrm{Li}^{\mathrm{b}}$, Dongfeng Wang ${ }^{\mathrm{c \#}}$

${ }^{\mathrm{a} C}$ College of Food Science, Fujian Agriculture and Forestry University, Fuzhou, 350002, PR, China

${ }^{\mathrm{b}}$ Division of Food Technology, National Food Institute, Technical University of Denmark, 2800 Kgs. Lyngby, Denmark

${ }^{\mathrm{c}}$ College of Food Science and Engineering, Ocean University of China, Qingdao, 266003, PR, China

*These authors are co-first author.

${ }^{\#}$ Correspondence should be addressed to College of Food Science and Engineering, Ocean University of China, No. 5, Yushan Road, Shinan District, Qingdao City, Shandong Province 266003, PR, China.

E-mail: wangdfouc@126.com

Tel/fax: +86 53282031575 


\section{ABSTRACT}

$\mathrm{La}^{3+}$ and mixed-rare earth magnetic chitosan beads (MCLB and MCLRB) were successfully prepared for fluoride removal, respectively. The adsorbents were characterized by scanning electron microscope and magnetic response. Batch experiments were carried out to investigate the adsorbent performance based on the influence of various factors such as adsorbent dosage, contact time, initial solution $\mathrm{pH}$ and co-existing anions on the fluoride adsorption. Results showed that MCLB and MCLRB followed the pseudo-second-order kinetic model with the correlation coefficient value of 0.9925 and 0.9985 respectively. The adsorption process was mainly chemical adsorption. The isotherm data was well fitted both Langmuir model and Freundlich model. The adsorption capacity of the adsorbents were 20.53 and $22.35 \mathrm{mg} / \mathrm{g}$ respectively. The optimum $\mathrm{pH}$ value for fluoride ion removal was 5.0. The effects of co-existing anions on the fluoride sorption followed the decreasing order of $\mathrm{CO}_{3}{ }^{2-}>\mathrm{HCO}_{3}{ }^{-}>\mathrm{SO}_{4}{ }^{2-}>\mathrm{NO}_{3}{ }^{-}>\mathrm{Cl}^{-}$. Fluoride adsorption on MCLB and MCLRB could be attributed to ion exchange between fluoride and -OH groups with the Fe-O coordinate bond promotion. Our study revealed that MCLB and MCLRB performed strong adsorption capacity for fluoride ion. In particularly, MCLRB could be a more cost-effective adsorbent to remove fluoride from aqueous solution.

Keywords: $\mathrm{La}^{3+}$; mixed rare earth; magnetic chitosan; fluoride removal 


\section{Introduction}

Fluoride has been reported to be beneficial for calcification of dental enamel and maintenance of healthy bones in human body at the concentration ranginge from 0.5 to $1.5 \mathrm{mg} / \mathrm{L}$, but it is considered to be a hazard when it exceeds $1.5 \mathrm{mg} / \mathrm{L}$ in drinking water. The WHO guideline on fluoride in drinking water also sets the permissible limit of $1.5 \mathrm{mg} / \mathrm{L}(0.079 \mathrm{mM})$ [1]. Currently, the occurrence of fluoride in drinking water is a worldwide problem and has attracted more and more attentions [2,3]. High fluoride concentration has been found in the ground waters, particularly in parts of India, China, Central Africa and South America [3]. Thus, many studies on defluorination were performed to remove the excess of fluoride effectively from drinking water [4].

Numerous treatment methods, including adsorption, ion exchange, precipitation, membrane and electro-dialysis, have been researched [5]. Among these methods, adsorption was found to be more suitable and effective for the defluoridation from drinking water due to its simplicity and selectivity $[6,7]$. Furthermore, adsorbents for fluoride removal have also been in development, such as carbon nanotubes [8], $\mathrm{La}^{3+}$-impregnated cross-linked gelatin [9], aluminum-impregnated carbon [10], magnetic-chitosan particle [11] and mixed rare earth oxides [12]. Besides these absorbents, the biosorption method of fluoride removal can be also effectively utilized. It obtains the advantages of low cost, less chemical and/or biological sludge to be disposed of. As far as we know, the material of chitosan is N-deacetylated derivative of chitin, which is non-toxic, biodegradable and biocompatible. Large amounts of 
chitosan derivatives have been used for defluorination, such as Al- Fe(III) chitosan hydrogel [13], Zr(IV)-chitosan [14], Ce(III)-chitosan [15], and lanthanum-chitosan [16]. Furthermore, rare earth ions have strong tendencies to dissociate $\mathrm{OH}$ groups into hydroxyl ions because of their relatively small ionic potential and strong basicity, which results in a promising ability for fluoride adsorption from water [17]. In our previous study, we have discussed a novel fluoride adsorbent with mixed rare earths modified chitosan which had a better ability for fluoride adsorption and even more cheaper than lanthanum modified chitosan.[18]. But this adsorbent is not easy to separate from water system after the adsorption process.

It has been reported that magnetic particle adsorbents can be developed for bio-separation and removal ions from aqueous solutions with excellent and controllable properties. Meanwhile, the magnetic particle can be easily and simply separated by the external magnetic field. According to the report, Ma et al. [19] synthesized and performed lanthanum immobilized magnetic-chitosan in powder form for fluoride adsorption from drinking water. The results showed lanthanum modified magnetic-chitosan could effectively improve the adsorption capacity. Meanwhile the material was easily separated, and reused after fluoride adsorption. While, for all we know, the flake form of chitosan is less stable, it can produce significant pressure drop, and affect filtration [20]. K. Fujiwara et al. researched to modify chitosan with various crosslinking agents to the form of chitosan beads or resin in the prepared methods [21]. However, little information has been reported on lanthanum or mixed rare earths modified chitosan for fluoride adsorption. 
In this present work, lanthanum or mixed rare earths modified chitosan beads (MCLB and MCLRB) were prepared by inverse suspension method for the first time. Besides, the effects of key operation parameters, such as $\mathrm{pH}$, contact time, initial concentration of fluoride, coexisting anions on fluoride removal, were also investigated in this study. In addition, the adsorption isotherm and adsorption kinetics were carried out to evaluate the fluoride adsorption process by MCLB and MCLRB. Furthermore, the fluoride removal mechanism was revealed and proposed in this work.

\section{Materials and methods}

\subsection{Materials}

Chitosan $\left(5.1 \times 10^{5}\right.$ Da viscosity average molecular weight, $5.4 \%$ deacetylated $)$ was purchased from Shandong Hecreat marine bio-tech Co., Ltd. (Qingdao, China). Acetic acid, $\mathrm{NaF}$ (as the source of $\mathrm{F}^{-}$), liquid paraffin, glutaraldehyde, dithiocarbamate, $\mathrm{FeSO}_{4} \cdot 7 \mathrm{H}_{2} \mathrm{O}, \mathrm{Fe}_{2}\left(\mathrm{SO}_{4}\right)_{3} \cdot \mathrm{xH}_{2} \mathrm{O}, \mathrm{La}\left(\mathrm{NO}_{3}\right)_{3}$ and all the other reagents used in this experiment were of analytical grade and conducted without any further purification. The mixed rare earths contain several elements, such as $\mathrm{La}, \mathrm{Ce}, \mathrm{Pr}$, and Sm with $\mathrm{La}$ $(3823.0 \mathrm{mg} / \mathrm{kg})$ and $\mathrm{Ce}(788.43 \mathrm{mg} / \mathrm{kg})$ as the major elements [18]. Deionized distilled water (18.2 M $\Omega$, Millipore) was used throughout the whole study.

\subsection{Preparation of Magnetic iron oxide synthesis}

$\mathrm{Fe}_{3} \mathrm{O}_{4}$ was synthesized by the chemical co-precipitation of ferric and ferrous ions under the alkaline condition of the water. In details, $7.396 \mathrm{~g} \mathrm{Fe}_{2}\left(\mathrm{SO}_{4}\right)_{3}{ }^{-} \cdot \mathrm{xH}_{2} \mathrm{O}$ was dissolved in $50 \mathrm{~mL}$ deionized water at $40{ }^{\circ} \mathrm{C}$, and 5.0 g FeSO $4 \cdot 7 \mathrm{H}_{2} \mathrm{O}$ was added to 
prevent the oxidation of $\mathrm{Fe}^{2+}$. The obtained black precipitates, i.e., $\mathrm{Fe}_{3} \mathrm{O}_{4}$, were washed with deionized water three times, and then collected and heated in air for $3 \mathrm{~h}$ at $150{ }^{\circ} \mathrm{C}$. The brown powder was collected after magnetic separation and kept away from light before using [22].

\subsection{Preparation of $M C L B$ and MCLRB}

MCLB and MCLRB were synthesized, according to our previous reported paper with a bit of modifications [23]. The preparation scheme of MCLB as similar as MCLRB was shown in Fig. 1. Briefly, $100.0 \mathrm{~g}$ of chitosan was added to the lanthanum nitrate solution $(100 \mathrm{~mL}, 1.0 \mathrm{~g} / \mathrm{mL})$ and blended for $3 \mathrm{~h}$. Then, the resulting solution was added to $100 \mathrm{~mL}$ acetic acid solution (4 vol.\%), and kept for 24 h. Next, liquid paraffin was added to form a dispersion phase. Formaldehyde and glutaraldehyde were added as crosslinking agents with the $\gamma-\mathrm{Fe}_{2} \mathrm{O}_{3}$ added at the same time. The reaction was continued for $4 \mathrm{~h}$. Finally, the mixture was filtered and washed three times by acetone, ethanol, and distilled water in sequence. MCLRB was synthesized the same as the MCLB, in which lanthanum nitrate was replaced by the rare earth with high content of $\mathrm{La}^{3+}$.

\subsection{Characterization of $M C L B$}

\subsubsection{SEM-EDX and BET analysis}

Scanning electron microscope (SEM) (JEOL, JXA-840A) was taken to analyze the surface structure and morphology of the MCLB and MCLRB. In addition, the energy dispersive X-ray (EDX) was taken to determine the elemental composition of the surface after $\mathrm{F}^{-}$adsorption at a voltage of $\sim 10 \mathrm{keV} \mathrm{[24].}$ 
The microstructure of the MCLB and MCLRB was further characterized by Brunauer-Emmett-Teller (BET) analysis. The BET surface area and average pore diameter analysis were tested using gas adsorption surface area and pore size analyzer (NOVA 1000e, Quantachrome Ins.) respectively according to the BET equation.

\subsubsection{Hysteresis loop of MCLB}

In this study, a small magnet was performed to observe the magnetic response between two sample bottles which were filled with magnetic adsorbents previously. In addition, the magnetic properties were characterized by superconducting quantum interference device (SQUID) magnetometer (MPMS-XL-7). $10.0 \mathrm{mg}$ of dried powder was placed in the device, measured at an applied field of $5000 \mathrm{G}$ over the temperature ranginge from $4 \mathrm{~K}$ to $300 \mathrm{~K}$, and measured again after coating with a lens wiping paper [25].

\subsection{Batch adsorption experiments}

Batch fluoride experiments were carried out in $50 \mathrm{~mL}$ Erlenmeyer flasks. $0.1 \mathrm{~g}$ adsorbent and $10 \mathrm{mg} / \mathrm{L} \mathrm{F}$ aqueous solution was added up to the volume of $50.0 \mathrm{~mL}$. The $\mathrm{pH}$ of aqueous solution was adjusted from 5.0 to 9.0 by adding $1.0 \mathrm{~mol} / \mathrm{L} \mathrm{NaOH}$ or $1.0 \mathrm{~mol} / \mathrm{L} \mathrm{HCl}$ aqueous solution and measured with a $\mathrm{pH}$ meter (Delta 320, Mettler-toledo). The batch experiments were carried out at a constant temperature for 24 h. After adsorption equilibration, the adsorbent was separated by filtration. The $\mathrm{F}^{-}$ concentration in the filtrate was determined by the method of $\mathrm{F}^{-}$selective electrode. The adsorption capacity of adsorbent for $\mathrm{F}^{-}$was calculated through the expression as Eq. (1) [26]: 


$$
q_{e}=\frac{\left(C_{0}-C\right) \times V}{W}
$$

where $q_{e}$ is the adsorption capacity of the adsorbents $(\mathrm{mg} / \mathrm{g}) ; C_{0}$ and $C$ are the concentrations of $\mathrm{F}^{-}$in the initial and equilibrium solution $(\mathrm{mg} / \mathrm{L})$, respectively; $V$ is the volume of $\mathrm{F}^{-}$aqueous solution (L) and $W$ is the weight of dry beads (g).

\subsection{Regeneration and stability of MCLB and MCLRB}

$0.1 \mathrm{~g}$ of MCLB and MCLRB was mixed into $50 \mathrm{~mL} 10 \mathrm{mg} / \mathrm{L} \mathrm{F}^{-}$solution reacting at $30{ }^{\circ} \mathrm{C}$ for $2 \mathrm{~h}$, and then soaked in $0.5 \mathrm{~mol} / \mathrm{L}$ sodium hydroxide solution for $12 \mathrm{~h}$ and rinsed with distilled water until neutral, drying to obtain the regeneration of defluoridators. The adsorption desorption regeneration was repeated for 7 times and the fluoride concentration in the solution was measured.

\subsection{Data accuracy}

Each $\mathrm{F}^{-}$adsorption experiment was conducted in triplicate so as to obtain reproducible results with an error of less than $5 \%$, and the original $\mathrm{F}^{-}$solution (control) was used in all the analysis. The residual $\mathrm{F}^{-}$concentration in the aqueous phase was analyzed.

\subsection{Statistic analysis}

The statistical analysis of the data was performed with Tukey's multiplecomparison test using a statistical package program Minitab 16 (Minitab Inc., State College, PA, USA). Significant differences were accepted at $\mathrm{P}<0.05$.

\section{Results and discussion}

\subsection{SEM-EDX and BET analysis}

The surface morphology of MCLB and MCLRB were illustrated in Fig.2 (a-d). It 
was clear to see that the surfaces of adsorbents were spherical (Fig. 2a and Fig. 2 c), smooth, and porosity (Fig. $2 b$ and Fig. 2 d), which increased the specific surface area of adsorbents and the adsorption capacity on fluoride ion [27]. As shown in Fig.3, the energy dispersive X-ray (EDX) analysis spectrum of MCLRB after fluoride ion adsorption, there was an obvious content of fluoride ion in the EDX spectrum after fluoride adsorption, which illustrated MCLRB was an efficient adsorbent for fluoride ion adsorption [28]. The surface area and average pore diameter for MCLB and MCLRB were shown in Table 1. MCLRB illustrated higher surface area compared to MCLB and they had similar mean pore diameter. Obviously, MCLRB showed more attractive advantages, and its uptake capacity would be higher due to its adsorption sites.

\subsection{Characterization of magnetic beads of adsorbents}

The magnetic analysis of adsorbents was shown in Fig.3. Both the adsorbents could be absorbed to the bottle walls of the magnetic field instantly, which demonstrated that they had strong magnetic responsiveness to the magnetic field. Thus they could be separated from aqueous solution quickly. The magnitude of the saturation magnetization of MCLB was around $5.17 \mathrm{emu} / \mathrm{g}$, but MCLRB was $9.90 \mathrm{emu} / \mathrm{g}$. MCLRB with $9.90 \mathrm{emu} / \mathrm{g}$ was also much higher than $\mathrm{MCH}$ with 6.0 emu/g [21]. Furthermore, the weak hysteresis phenomenon for MCLB and MCLRB suggested that the resultant MCLB and MCLRB were nearly super paramagnetic [25, 29].

\subsection{Adsorption fluoride ion on different adsorbents}


As shown in Fig. 5, the $\mathrm{F}^{-}$adsorption capacities on CTS and MCB (magnetic chitosan beads) were increased significantly $(\mathrm{P}<0.05)$ after modification by $\mathrm{La}^{3+}$, especially rare earth modified of magnetic chitosan beads. The adsorption capacity of $\mathrm{F}^{-}$on $\mathrm{CTS}$ and $\mathrm{MCB}$ were $0.10,1.63 \mathrm{mg} / \mathrm{g}$, respectively. Surprisingly, it was increased to be $3.52,3.80 \mathrm{mg} / \mathrm{g}$ with MCLB and MCLRB, separately. These results suggested that $\mathrm{La}^{3+}$ and mixed rare earth played a key role in adsorption process of $\mathrm{F}^{-}$.

\section{3..5 Effect of pH on fluoride ion adsorption}

The effect of $\mathrm{pH}$ on fluoride ion sorption plays an important role in the adsorption of fluoride ion at the adsorbent-water interface and was related to the $\mathrm{pH}_{\mathrm{zpc}}$ (the $\mathrm{pH}$ point of zero charge) of the adsorbents [30]. Thus, the $\mathrm{F}^{-}$adsorption onto both MCLB and MCLRB were performed at five different $\mathrm{pH}$ levels of 5.0, 6.0, 7.0, 8.0 and 9.0 by keeping other parameters such as contact time and initial fluoride ion concentration the same. Fig. 6 displayed that the maximum adsorption capacity was recorded at $\mathrm{pH} 5.0$, and then showed a decrease within the range of $\mathrm{pH}$ 5.0-9.0, which was in accordance with the previous work [29]. The fluoride adsorption of MCLRB was higher than MCLB, which was similar to our previous report. With the increase of $\mathrm{pH}$, the $\mathrm{OH}^{-}$concentration in the aqueous solution was increased. And then $\mathrm{OH}^{-}$ could compete with $\mathrm{F}^{-}$for the adsorption sites on the surface of adsorbents, which lead to a decline of the $\mathrm{F}^{-}$adsorption capacity [30]. The adsorption of $\mathrm{F}^{-}$onto adsorbents were achieved with the anion exchange between $\mathrm{OH}^{-}$and $\mathrm{F}^{-}$. In addition, Lewis acid-base interaction could also play an important role in the adsorption process mentioned above [31]. According to the literatures [32, 33], fluoride 
adsorbents were performed under $\mathrm{pH}$ 5.0 7.0, which demonstrated that $\mathrm{F}^{-}$adsorbents could be utilized under $\mathrm{pH}$ 7.0.

Chitosan (CTS) and its derivatives are usually cationic organic polymer adsorbents. Under acidic conditions, the negative charge of heavy metal ions decreases, which leads to the decrease of neutralization capacity. Under alkaline conditions, the negative charge of the solution is increased, but the adsorbent molecule contains amide group, which is partly hydrolyzed to carboxyl after alkalization, and the adsorption is decreased. In particular, MCLRB was more effective to adsorb $\mathrm{F}^{-}$from Fig. 6 , thus it was promising to be utilized in the future. This result obtained was similar to our previous report [18]. Hence, all subsequent studies could be conducted with neutral aqueous solution.

\subsection{Effect of the presence of co-anions}

In the practical application, the $\mathrm{F}^{-}$contaminated water or aqueous solution contains other coexisting anions, which can compete with $\mathrm{F}^{-}$in the adsorption process [34]. The concentration of common anions was $200 \mathrm{mg} / \mathrm{L}$ with reference to the national standard of groundwater quality (GB/T14848-93). The adsorption experiments were carried out in the presence of $200 \mathrm{mg} / \mathrm{L}$ salt solutions of $\mathrm{SO}_{4}{ }^{2-}$, $\mathrm{CO}_{3}^{2-}, \mathrm{NO}_{3}^{-}, \mathrm{Cl}^{-}$, and $\mathrm{HCO}_{3}^{-}$, separately. Results were displayed in Fig. 7. The existence of these anions had a negative effect on the adsorption of $\mathrm{F}^{-}$. The presence of $\mathrm{Cl}^{-}$decreased the adsorption capacity onto MCLB and MCLRB from 3.16, 3.67 $\mathrm{mg} / \mathrm{g}$ to $2.65,3.44 \mathrm{mg} / \mathrm{g}$, respectively, which indicated that $\mathrm{Cl}^{-}$had less influence of adsorption. However, $\mathrm{CO}_{3}{ }^{2-}$ decreased $\mathrm{F}^{-}$adsorption capacity significantly, the same as 
$\mathrm{HCO}_{3}{ }^{-}$, which indicating that $\mathrm{CO}_{3}{ }^{2-}$ and $\mathrm{HCO}_{3}{ }^{-}$showed an adverse effect on the $\mathrm{F}^{-}$ adsorption process [35]. This phenomenon could be explained that the coexistence anions could compete the $\mathrm{F}^{-}$adsorption sites on the surface of adsorbents [36]. In addition, increasing the concentration of $\mathrm{CO}_{3}{ }^{2-}$ and $\mathrm{HCO}_{3}{ }^{-}$could raise the $\mathrm{pH}$ of the aqueous solution. Hence, $\mathrm{F}^{-}$adsorption capacity onto adsorbents decreased, significantly [37].

\subsection{Effect of contact time on fluoride ion adsorption}

The effect of contact time on $\mathrm{F}^{-}$adsorption was shown in Fig. 8, the adsorption studies were performed for contact time ranging from 10 to $500 \mathrm{~min}$. It was clear that the adsorption capacity of $\mathrm{F}^{-}$onto adsorbents increased with an increasing of contact time and reached adsorption equilibrium at approximately $120 \mathrm{~min}$. The adsorption process could be divide into two stages, an initial rapid stage where adsorption was quick to equilibrium uptake. It was illustrated the fast adsorption was achieved in a short time [38], and second stage was slower due to the total metal adsorption sites being really small. It could be interpreted as the gradual adsorption stage where intraparticle diffusion controls the adsorption rate until the adsorption sites reach equilibrium finally [39]. After $120 \mathrm{~min}$, the change of adsorption capacity was not obvious. As a result, this time was chosen for the further adsorption experiments.

In the case of $\mathrm{F}^{-}$, the time dependent adsorption data at $30{ }^{\circ} \mathrm{C}$ was analyzed by two different adsorption kinetic models such as the pseudo-first-order model and pseudo-second-order model [40].

The linear form of pseudo-first-order mode is given as [41]: 
$\log \left(q_{e}-q_{t}\right)=\log q_{e}-\frac{\mathrm{K}_{1} \mathrm{t}}{2.303}$

where $q_{e}$ is the equilibrium adsorption capacity $(\mathrm{mg} / \mathrm{g}) ; q_{t}$ is the adsorption capacity of $t(\mathrm{mg} / \mathrm{g}) ; K_{l}$ is the rate constant of the pseudo-first order kinetic equation $\left(\min ^{-1}\right)$.

The calculated values $K_{l}, q_{e}$ and correlation coefficients $\left(R^{2}\right)$ of typical pseudo-first-order model at $30^{\circ} \mathrm{C}$ are listed in Table 2 .

The pseudo-second order kinetic model equation is expressed as Eq. (3) [42]:

$$
\frac{t}{q_{t}}=\frac{1}{K_{2} q_{e}^{2}}+\frac{t}{q_{e}}
$$

In this equation, $K_{2}$ is the rate constant of the pseudo-second order kinetic equation $\left(\mathrm{min}^{-1}\right)$ and the other parameters are consistent with the first order kinetic parameters.

Based on the data of Fig. 8, plots of $t / q_{t}$ versus $t$ for the adsorption of $\mathrm{F}^{-}$were obtained and shown in Fig. 9. The pseudo-first-order and pseudo-second-order kinetic model rate constants for adsorption of $\mathrm{F}^{-}$were summarized and displayed in Table 2. From Table 2, the calculated $R^{2}$ from pseudo-first-order kinetic model was much lower than that of pseudo-second-order kinetic model. This result demonstrated that $\mathrm{F}^{-}$ adsorption onto adsorbents was better expressed by pseudo-second-order kinetic model than pseudo-first-order kinetic model. In particular, MCLRB was better described than MCLB. The pseudo-second-order kinetic model assumed that chemical adsorption should be the rate-limiting step in the adsorption process [43]. In addition, the data of initial adsorption rate illustrated that the $\mathrm{F}^{-}$adsorption onto MCLRB was faster than MCLB. 


\subsection{Effect of concentration on fluoride ion adsorption}

In this study, the effect of initial $\mathrm{F}^{-}$concentration on the adsorption capacity of MCLB and MCLRB were carried out by adding $0.1 \mathrm{~g}$ adsorbent into $25 \mathrm{ml}$ aqueous solution at $30{ }^{\circ} \mathrm{C}$, separately. The results were shown in Fig. 10. It was clear that the $\mathrm{F}^{-}$adsorption capacity onto adsorbents increased when increasing the initial concentration of $\mathrm{F}^{-}$in the aqueous solution. This result was consistent with the reported study on adsorption of $\mathrm{F}^{-}$from aqueous solution [14]. Furthermore, the adsorption isotherm study was evaluated by Langmuir adsorption isotherm model and Freundlich adsorption isotherm model.

Langmuir adsorption isotherm model assumes that the homogenous adsorption occurs on a monolayer surface coverage, and no interaction exists between the adsorbed species. The linearized Langmuir equation is expressed in Eq. (4) and (5) [44]:

$$
\begin{aligned}
& q_{e}=\frac{Q_{\max } K_{L} C_{e}}{1+K_{L} C_{e}} \\
& \frac{1}{q_{e}}=\frac{1}{Q_{\max } K_{L} C_{e}}+\frac{1}{Q_{\max }}
\end{aligned}
$$

where $q_{e}(\mathrm{mg} / \mathrm{g})$ is the equilibrium adsorption capacity $(\mathrm{mg} / \mathrm{g}) ; C_{e}$ is the concentrations of fluoride in the equilibrium solution $(\mathrm{mg} / \mathrm{L}) ; Q_{\max }(\mathrm{mg} / \mathrm{g})$ is the saturated adsorption capacity and $K_{L}(\mathrm{~L} / \mathrm{mg})$ is the Langmuir adsorption constant, which related to the free energy of adsorption.

The Freundlich isotherm assuming an exponentially decaying adsorption site energy distribution and applicable to non-ideal adsorption on heterogeneous surfaces showing multi-layer adsorption is written as Eq. (6) [45]: 


$$
\lg q_{e}=\frac{1}{n} \lg C_{e}+\lg K_{F}
$$

where $q_{e}$ is the amount of fluoride adsorbed $(\mathrm{mg} / \mathrm{g})$ at equilibrium, $C_{e}(\mathrm{mg} / \mathrm{L})$ is the final concentration at equilibrium, $K_{F}$ is the Freundlich adsorption constant $[(\mathrm{mg} / \mathrm{g})$ $\left.(\mathrm{mg} / \mathrm{L})^{1 / n}\right], n$ is Freundlich constants relatedto adsorption capacity and heterogeneity factor, respectively. $K_{2}$ and $n$ values could be calculated from the intercept and slope of the linear plot between $\log C_{e}$ and $\log q_{e}$

The isotherm constants and correlation coefficients $\left(R^{2}\right)$ for linear Langmuir and Freundlich equations were given in Table 3 . Based on the $R^{2}$ values, the Freundlich isotherm model was better to show $R^{2}$ values than the Langmuir model. The Freundlich isotherm model for adsorption of $\mathrm{F}^{-}$onto MCLB and MCLRB were presented in Fig. 11, the straight lines of plots indicated that the adsorption processes of all cases could be well described by Freundlich isotherm model. This implied the multi-layer adsorption of $\mathrm{F}^{-}$onto homogeneous active sites on the surface of the MCLB and MCLRB. Besides, the maximum adsorption capacities of MCLB and MCLRB for $\mathrm{F}^{-}$removal were estimated to be $20.53 \mathrm{mg} / \mathrm{g}, 22.35 \mathrm{mg} / \mathrm{g}$, respectively. It suggested that in this temperature MCLRB was an efficient adsorbent for $\mathrm{F}^{-}$removal in this temperature. This might be due to the stronger interaction between $\mathrm{F}^{-}$and the surface components of the MCLRB, and the Fe-O could also promote $\mathrm{F}^{-}$moving towards the surface of MCLRB.

In particular, the essential properties of Langmuir isotherm model could be expressed in terms of dimensionless constant separation factor $R_{L}$, which is performed to predict when an adsorption system is 'unfavorable', 'favorable', 'irreversible' or 
'linear'. The separation factor $R_{L}$ is expressed as Eq. (7).

$$
R_{L}=\frac{1}{1+K_{b} C_{0}}
$$

where $R_{L}$ refers to the favorability and the capacity of the adsorbent/adsorbate system, $C_{0}(\mathrm{mg} / \mathrm{L})$ is the initial $\mathrm{F}^{-}$concentration and $K_{b}(\mathrm{~L} / \mathrm{mmol})$ is the Langmuir adsorption equilibrium constant. The $R_{L}$ value is classified as $R_{L}>1,0<R_{L}<1, R_{L}=0$, and $R_{L}=1$, which suggests that the adsorption was unfavorable, favorable, irreversible and linear, separately. In this study, both MCLB and MCLRB, the $R_{L}$ values were all between 0 and 1 for $\mathrm{F}^{-}$removal, which indicated that the uptake of $\mathrm{F}^{-}$onto adsorbents were favorable.

\subsection{Adsorption thermodynamics}

According to Henry's law, the activity coefficient remains constant in a low concentration solution. The thermodynamic parameters of the adsorption process can be calculated by the following formula:

$$
\begin{aligned}
& \Delta G^{o}=-R T \ln K_{c} \\
& \ln K_{c}=\frac{\Delta S^{0}}{R}-\frac{\Delta H^{0}}{R T}
\end{aligned}
$$

where $R$ is the gas constant, $T$ is the temperature and $K_{c}$ is the equilibrium constant. The initial fluorine concentration is $200 \mathrm{mg} / \mathrm{L}$, and the thermodynamic parameters were as follows: $\Delta G_{0}<0$, indicating that the adsorption of fluoride ions was a spontaneous process, and $\Delta H_{0}$ was $7.89 \mathrm{~kJ} / \mathrm{mol}$ (Table 4 ), which showed that adsorption of fluorine ions was endothermic process. According to the theory of adsorption for solid-liquid adsorption, solute molecules from the liquid phase to the 
solid-liquid interface exchange will lose a degree of freedom, leading to the decrease of entropy, $\Delta S_{0}<0$ in line with the theory.

\subsection{Measurement of released elements into solution at various $\mathrm{pH}$}

The release of elements under different $\mathrm{pH}$ conditions was shown in Fig. 12. When $\mathrm{pH}$ was 5 , the lanthanum ion was released most, and with the increase of $\mathrm{pH}$, the concentration of lanthanum ion in the solution decreased slowly. This was because when $\mathrm{pH}$ was lower, the hydrogen ion increased, and it was easy to be protonated. The hydrogen ion affected the adsorption ability of rare earth ions on chitosan, and the concentration of lanthanum ion in solution was higher.

\subsection{Regeneration and stability}

The study on the regeneration of fluoride removal agent can help explain the recycling performance of the adsorbents. The application of MCLB and MCLRB are to be desorbed and reused. As shown in Fig. 13, MCLB and MCLRB could be reused several times after adsorption. The regeneration effect on MCLRB was better than that of MCLB. After several times of regeneration, the adsorption of $\mathrm{F}^{-}$still had good adsorption ability. The adsorption performance was stable.

\subsection{Adsorption mechanism}

Lanthanum rare earth ions had better affinity to $\mathrm{F}^{-}$and coordinated with it to form a stable complex [46]. $\mathrm{La}^{3+}$ has a hydrolysis reaction in water and get hydration coordination rare earth ions $\mathrm{La}\left(\mathrm{H}_{2} \mathrm{O}\right)^{2+}$. Under above conditions, the $\mathrm{pH}$ is about 4.0 4.5 in water. When chitosan is suspended in the above water system of $\mathrm{La}\left(\mathrm{H}_{2} \mathrm{O}\right)^{2+}$ then the amino groups will be protonated. The chitosan and $\mathrm{La}\left(\mathrm{H}_{2} \mathrm{O}\right)^{2+}$ coordinate to 
be MCLB containing Fe-O coordinate bond eventually. The same as MCLRB, which contained the majority elements of $\mathrm{La}^{3+}$ rare eaths modified-magnetic chitosan beads. $\mathrm{Fe}-\mathrm{O}$ coordinate bond could promote $\mathrm{F}^{-}$to move towards the surface of adsorbents adsorption sites. $\mathrm{F}^{-}$replaced the group of $-\mathrm{OH}$ which belonged to $\mathrm{Ln}\left(\mathrm{H}_{2} \mathrm{O}\right) \mathrm{n}-\mathrm{m}(\mathrm{OH})$ m (n-2), and had an ion exchange. Therefore, the adsorption mechanism of MCLB, similar to MCLRB, was proposed and shown in Fig. 14.

\section{Conclusion}

$\mathrm{La}^{3+}$ and mixed rare earths with high content of $\mathrm{La}^{3+}$ modified magnetic chitosan beads (MCLB and MCLRB) were synthesized successfully to adsorbe $\mathrm{F}^{-}$from aqueous solution. Adsorption kinetics experiment demonstrated that the adsorption equilibrium were reached within $120 \mathrm{~min}$. A better $\mathrm{F}^{-}$adsorption capacity obtained at low $\mathrm{pH}$ (5.0 7.0). The maximum adsorption capacity of $20.53 \mathrm{mg} / \mathrm{g}, 22.35 \mathrm{mg} / \mathrm{g}$ were achieved at $\mathrm{pH} 7.0$ with the contacting time of $120 \mathrm{~min}$, which outperformed numerous reported literatures. The presence of $\mathrm{CO}_{3}{ }^{2-}$ and $\mathrm{HCO}_{3}{ }^{-}$reduced defluoridation capacity of adsorbents, while $\mathrm{SO}_{4}{ }^{2-}, \mathrm{NO}_{3}{ }^{-}$, and $\mathrm{Cl}^{-}$showed slight effect. The SEM-EDX and magnetic responsiveness showed that both MCLB and MCLRB were efficient adsorbents for $\mathrm{F}^{-}$adsorption. In addition, EDX illustrated MCLRB could adsorb $\mathrm{F}^{-}$effectively from aqueous solution. The mechanism was considered to be ligand exchange between $\mathrm{F}^{-}$and $-\mathrm{OH}$ in which $\mathrm{Fe}-\mathrm{O}$ was also involved to promote $\mathrm{F}^{-}$onto the adsorption sites. Results of this study suggested that MCLB and MCLRB are useful fluoride adsorbents. In particular, MCLRB is more effective and low-cost adsorbent to removal $\mathrm{F}^{-}$from aqueous solution when compare 
with MCLB.

\section{Conflict of interest}

The authors confirm that there is no conflict of interest in this article.

\section{Acknowledgements}

This study was funded by the Natural Science Foundation of Fujian Province (2016J01106) and the Fujian Educational Bureau (JA14109).

\section{References}

[1] M.E. Ravančić, M. Habuda-Stanić, Equilibrium and kinetics studies for the adsorption of fluoride onto commercial activated carbons using fluoride ion selective electrode, Int. J. Electrochem. Sci. 10(10) (2015) 8137-8149.

[2] S.Y. Zhang, Y.L. Yu, X.S. Su, Y.Y. Bian, B,W. Yu, Y.L. Zhang, Removal of fluoride ion from groundwater by adsorption on lanthanum and aluminum loaded clay adsorbent, Environ. Earth. Sci. 75(5) (2016) 1-9.

[3] A.D. Atasoy, M.I. Yesilnacar, M.O. Sahin, Removal of fluoride from contaminated ground water using raw and modified bauxite, B. Environ. Contam. Tox. 91(5) (2013) 595-599.

[4] Y. Li, Q. Du, J. Wang, T. Liu, J. Sun, Y. Wang, Z. Wang, Y. Xia, L. Xia, Defluoridation from aqueous solution by manganese oxide coated graphene oxide, J. Fluorine. Chem. 148 (2013) 67-73.

[5] M. Barathi, A.S. Kumar, N. Rajesh, A novel ultrasonication method in the preparation of zirconium impregnated cellulose for effective fluoride adsorption, Ultrason. Sonochem. 21 (2014) 1090-1099. 
[6] A. Teutli-Sequeira, V. Martínez-Miranda, M. Solache-Ríos, I. Linares-Hernández, Aluminum and lanthanum effects in natural materials on the adsorption of fluoride ions, J. Fluorine. Chem. 148 (2013) 6-13.

[7] Y. Shan, H. Guo, Fluoride adsorption on modified natural siderite: Optimization and performance, Chem. Eng. J. 223 (2013) 183-191.

[8] Y.H. Li, S. Wang, X. Zhang, J. Wei, C. Xu, Z. Luan, D. Wu, Adsorption of fluoride from water by aligned carbon nanotubes, Mater. Res. Bull. 38(3) (2003) 469-476.

[9] Y. Zhou, C. Yu, Y. Shan, Adsorption of fluoride from aqueous solution on $\mathrm{La}^{3+}$-impregnated cross-linked gelatin, Sep. Purif. Technol. 36(2) (2004) 89-94.

[10] R. Leyva Ramos, J. Ovalle-Turrubiartes, M. Sanchez-Castillo, Adsorption of fluoride from aqueous solution on aluminum-impregnated carbon, Carbon 37(4) (1999) 609-617.

[11] W. Ma, F.Q. Ya, M. Han, R. Wang, Characteristics of equilibrium, kinetics studies for adsorption of fluoride on magnetic-chitosan particle, J. Hazard. Mater. 143(1) (2007) 296-302.

[12] A. Raichur, M. Jyoti Basu, Adsorption of fluoride onto mixed rare earth oxides, Sep. Purif. Technol. 24(1) (2001) 121-127.

[13] J. Ma, Y. Shen, C. Shen, Y. Wen, W. Liu, Al-doping chitosan-Fe (III) hydrogel for the removal of fluoride from aqueous solutions, Chem. Eng. J. 248 (2014) 98-106.

[14] B. Liu, D. Wang, G. Yu, X. Meng, Removal of $\mathrm{F}^{-}$from aqueous solution using 
Zr (IV) impregnated dithiocarbamate modified chitosan beads, Chem. Eng. J. 228 (2013) 224-231.

[15] L. Jinfang, L. Qian, R. Huang, W. Guodong, Synthesis of a novel Ce (III)-incorporated cross-linked chitosan and its effective removal of fluoride from aqueous solution, J. Rare. Earth. 34(10) (2016) 1053-1061.

[16] S.P. Kamble, S. Jagtap, N.K. Labhsetwar, D. Thakare, S. Godfrey, S. Devotta, S.S. Rayalu, Defluoridation of drinking water using chitin, chitosan and lanthanum-modified chitosan, Chem. Eng. J. 129(1) (2007) 173-180.

[17] Y. Zhang, M. Yang, X.M. Dou, H. He, D.S. Wang, Arsenate adsorption on an Fe-Ce bimetal oxide adsorbent: role of surface properties, Environ. Sci. Technol. 39(18) (2005) 7246-7253.

[18] P. Liang, Y. Zhang, W. Dongfeng, X. Ying, L. Lan, Preparation of mixed rare earths modified chitosan for fluoride adsorption, J. Rare. Earth. 31(8) (2013) $817-822$

[19] W. Ma, F.Q. Ya, M. Han, R. Wang, Characteristics of equilibrium, kinetics studies for adsorption of fluoride on magnetic-chitosan particle, J. Hazard. Mater. 143(1) (2007) 296-302.

[20] E. Kusrini, N. Sofyan, N. Suwartha, G. Yesya, C.R. Priadi, Chitosan-praseodymium complex for adsorption of fluoride ions from water, J. Rare. Earth. 33(10) (2015) 1104-1113.

[21] K. Fujiwara, A. Ramesh, T. Maki, H. Hasegawa, K. Ueda, Adsorption of platinum (IV), palladium (II) and gold (III) from aqueous solutions onto 1-lysine 
modified crosslinked chitosan resin, J. Hazard. Mater. 146(1) (2007) 39-50.

[22] P. Rao, I.M. Lo, K. Yin, S.C. Tang, Removal of natural organic matter by cationic hydrogel with magnetic properties, J. Environ. Manage. 92(7) (2011) 1690-1695.

[23] Y. Zhang, X. Ying, C. Hao, L. Bingjie, G. Xiang, W. Dongfeng, P. Liang, La (III)-loaded bentonite/chitosan beads for defluoridation from aqueous solution, J. Rare. Earth. 32(5) (2014) 458-466.

[24] G. Vázquez, O. Mosquera, M.S. Freire, G. Antorrena, J. González-Álvarez, Alkaline pre-treatment of waste chestnut shell from a food industry to enhance cadmium, copper, lead and zinc ions removal, Chem. Eng. J. 184 (2012) 147-155.

[25] Y. Zhu, D. Wang, Rapid detection of Enterobacter Sakazakii in milk powder using amino modified chitosan immunomagnetic beads, Int. J. Biol. Macromol. 93 (2016) 615-622.

[26] S. Chatterjee, S. De, Adsorptive removal of fluoride by activated alumina doped cellulose acetate phthalate (CAP) mixed matrix membrane, Sep. Purif. Technol. 125 (2014) 223-238.

[27] N.A. Travlou, G.Z. Kyzas, N.K. Lazaridis, E.A. Deliyanni, Graphite oxide/chitosan composite for reactive dye removal, Chem. Eng. J. 217 (2013) 256-265.

[28] H. Paudyal, B. Pangeni, K.N. Ghimire, K. Inoue, K. Ohto, H. Kawakita, S. Alam, Adsorption behavior of orange waste gel for some rare earth ions and its 
application to the removal of fluoride from water, Chem. Eng. J. 195 (2012) 289-296.

[29] S. Dong, Y. Wang, Characterization and adsorption properties of a lanthanum-loaded magnetic cationic hydrogel composite for fluoride removal, Water. Res. 88 (2016) 852-860.

[30] H. Jin, Z. Ji, J. Yuan, J. Li, M. Liu, C. Xu, J. Dong, P. Hou, S. Hou, Research on removal of fluoride in aqueous solution by alumina-modified expanded graphite composite, J. Alloy. Compd. 620 (2015) 361-367.

[31] L. Zhang, Q. Zhou, J. Liu, N. Chang, L. Wan, J. Chen, Phosphate adsorption on lanthanum hydroxide-doped activated carbon fiber, Chem. Eng. J. 185 (2012) $160-167$.

[32] A. Vázquez-Guerrero, R. Alfaro-Cuevas-Villanueva, J.G. Rutiaga-Quiñones, R. Cortés-Martínez, Fluoride removal by aluminum-modified pine sawdust: effect of competitive ions, Ecol. Eng. 94 (2016) 365-379.

[33] D. Tang, G. Zhang, Efficient removal of fluoride by hierarchical Ce-Fe bimetal oxides adsorbent: thermodynamics, kinetics and mechanism, Chem. Eng. J. 283 (2016) 721-729.

[34] Q. Liu, L. Zhang, B. Yang, R. Huang, Removal of fluoride from aqueous solution using Zr (IV) immobilized cross-linked chitosan, Int. J. Biol. Macromol. 77 (2015) 15-23.

[35] J. Wang, X. Lin, X. Luo, Y. Long, A sorbent of carboxymethyl cellulose loaded with zirconium for the removal of fluoride from aqueous solution, Chem. Eng. J. 
252 (2014) 415-422.

[36] M. Nazari, R. Halladj, Adsorptive removal of fluoride ions from aqueous solution by using sonochemically synthesized nanomagnesia/alumina adsorbents: An experimental and modeling study, J. Taiwan. Inst. Cheme. 45 (5) (2014) 2518-2525.

[37] C. Yang, L. Gao, Y. Wang, X. Tian, S. Komarneni, Fluoride removal by ordered and disordered mesoporous aluminas, Micropor. Mesopor. Mat. 197 (2014) 156-163.

[38] V. Tomar, S. Prasad, D. Kumar, Adsorptive removal of fluoride from water samples using Zr-Mn composite material, Microchem. J. 111 (2013) 116-124.

[39] H. Hori, Y. Nagano, M. Murayama, K. Koike, S. Kutsuna, Efficient decomposition of perfluoroether carboxylic acids in water with a combination of persulfate oxidant and ultrasonic irradiation, J. Fluorine. Chem. 141 (2012) 5-10.

[40] S. Zhang, Y. Lu, X. Lin, X. Su, Y. Zhang, Removal of fluoride from groundwater by adsorption onto La (III)-Al (III) loaded scoria adsorbent, Appl. Surf. Sci. 303 (2014) 1-5.

[41] J. Cheng, X. Meng, C. Jing, J. Hao, $\mathrm{La}^{3+}$-modified activated alumina for fluoride removal from water, J. Hazard. Mater. 278 (2014) 343-349.

[42] X. Yu, S. Tong, M. Ge, J. Zuo, Removal of fluoride from drinking water by cellulose@hydroxyapatite nanocomposites, Carbohyd. Polym. 92(1) (2013) 269-275.

[43] F. C. Wu, R. L. Tseng, R. S. Juang, Enhanced abilities of highly swollen chitosan 
beads for color removal and tyrosinase immobilization, J. Hazard. Mater. 81(1) (2001) 167-177.

[44] I. Langmuir, The constitution and fundamental properties of solids and liquids. Part II.-Liquids, J. Am. Chem. Soc. 38(5) (1915) 102-105.

[45] D. Santra, R. Joarder, M. Sarkar, Taguchi design and equilibrium modeling for fluoride adsorption on cerium loaded cellulose nanocomposite bead, Carbohyd. Polym. 111 (2014) 813-821.

[46] P.G. Nelson, A modern version of Lewis's theory of valency, Found. Chem. $17(2)(2015)$ 153-162. 


\section{Figure captions}

Fig. 1 Preparation procedure scheme of magnetic chitosan beads loaded $\mathrm{La}^{3+}$ or mixed-rare earths for fluoride ion removal.

Fig. 2 SEM micrographs of MCLB: (a) SEM image $(\times 1500)$, (b) SEM image $(\times 100$, 000); MCLRB: (c) SEM image $(\times 1500)$, (d) SEM image $(\times 100,000)$.

Fig. 3 EDX micrographs of MCLRB after fluoride absorption.

Fig. 4 Magnetic hysteresis loop of MCLB and MCLRB.

Fig. 5 Fluoride adsorption capacity of different adsorbents with the same $\mathrm{pH}$, reaction time and temperature.

Fig. 6 Effect of fluoride adsorption capacity of MCLB and MCLRB with initial pH.

Fig. 7 Effect of anions on fluoride adsorption capacity of MCLB and MCLRB.

Fig. 8 Effect of fluoride adsorption capacity on MCLB and MCLRB with contact time.

Fig. 9 Plots for pseudo-second-order kinetic model.

Fig. 10 Effect of initial fluoride concentration on absorption capacity of MCLB and MCLRB for fluoride removal.

Fig. 11 Freundlich adsorption isotherm of fluoride sorption on MCLB and MCLRB.

Fig. 12 Measurement of released elements into solution at various $\mathrm{pH}$

Fig. 13 Relationship between reuse times and fluoride adsorption capacity of MCLB and MCLRB.

Fig. 14 Schematic description of fluoride adsorption by MCLB and MCLRB. 


\section{Tables:}

Table 1 BET surface area and average pore diameter of MCLB and MCLRB.

Table 2 The values of kinetic parameters for pseudo-first-order equation and pseudo-second-order equation together with correlation coefficients.

Table 3 Langmuir isotherm and Freundlich isotherm parameters for the adsorption of fluoride onto MCLB and MCLRB.

Table 4 The standard thermodynamic parameters of the sorption of MCLB and MCLRB. 
Figure graphics

Fig. 1

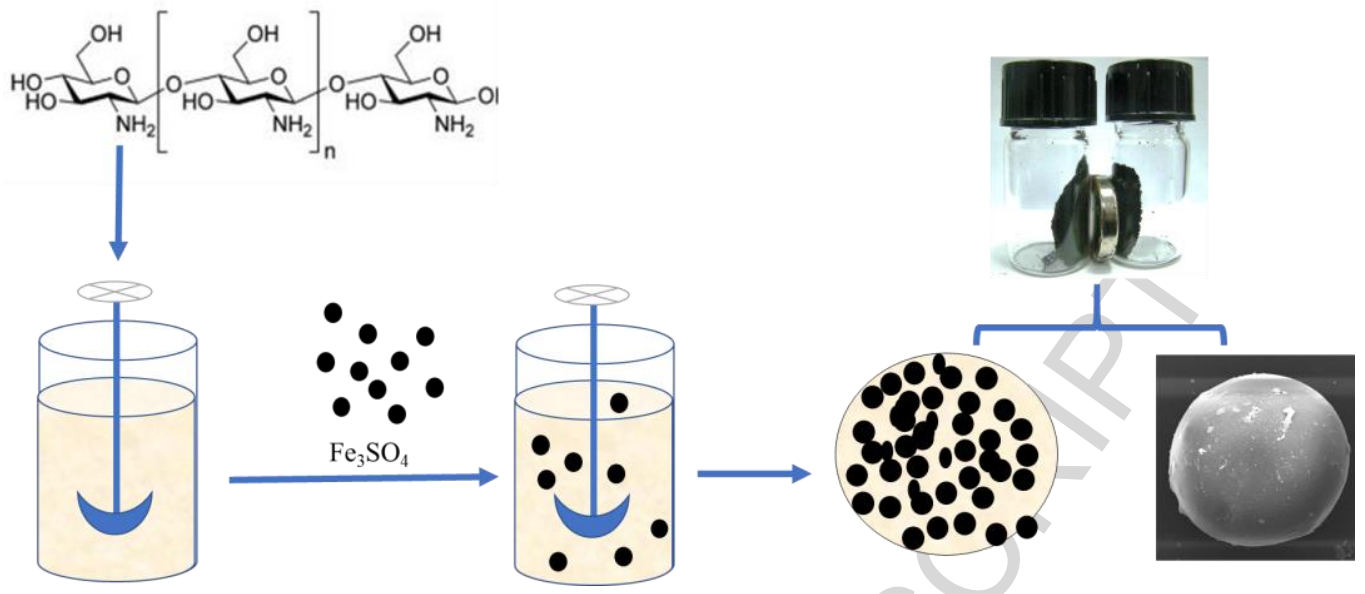


Fig. 2
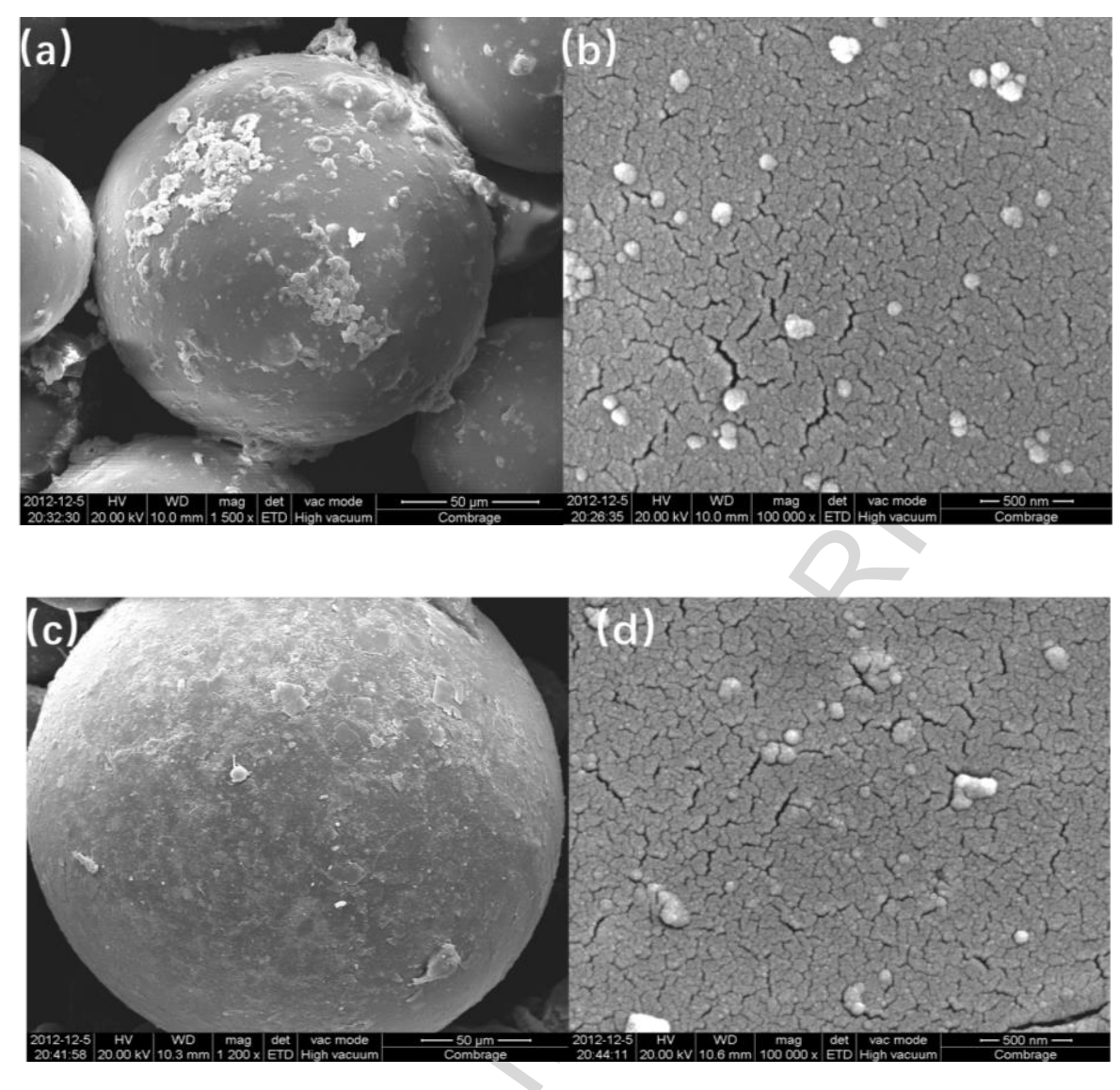
Fig.3

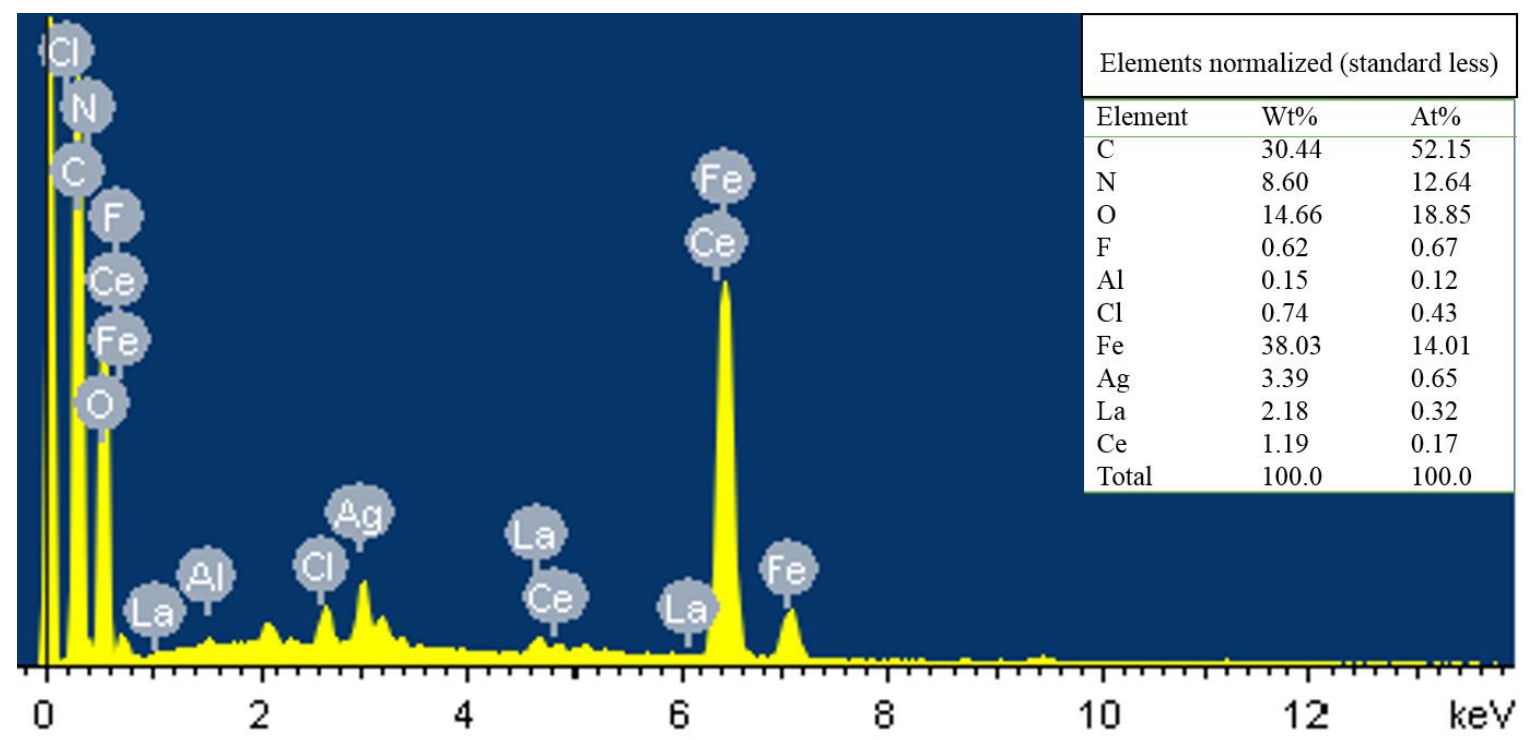


Fig.4
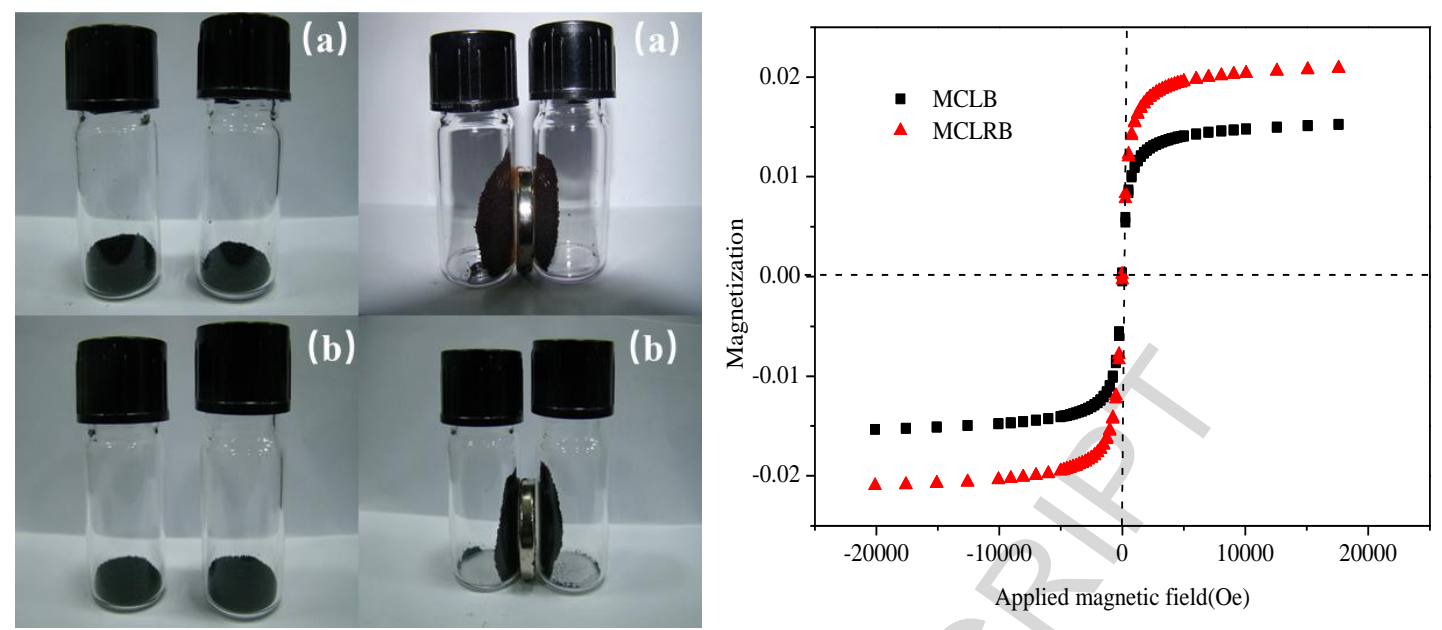
Fig. 5

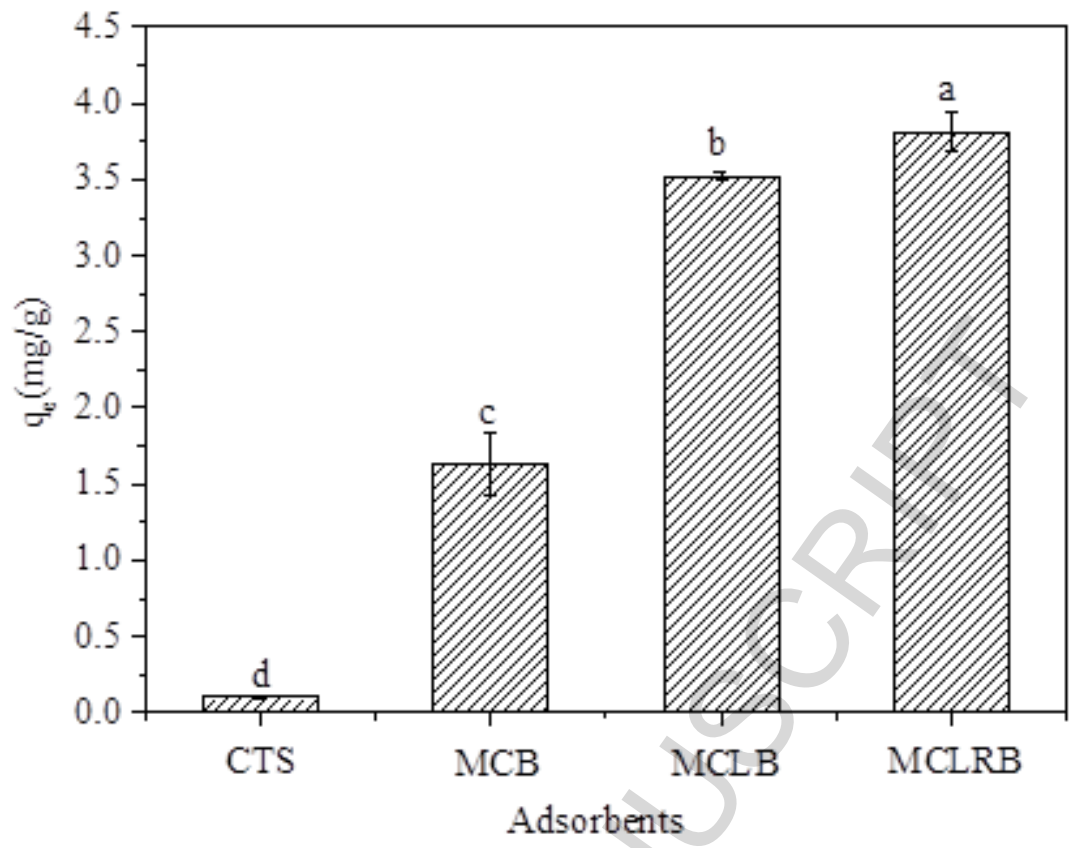


Fig. 6

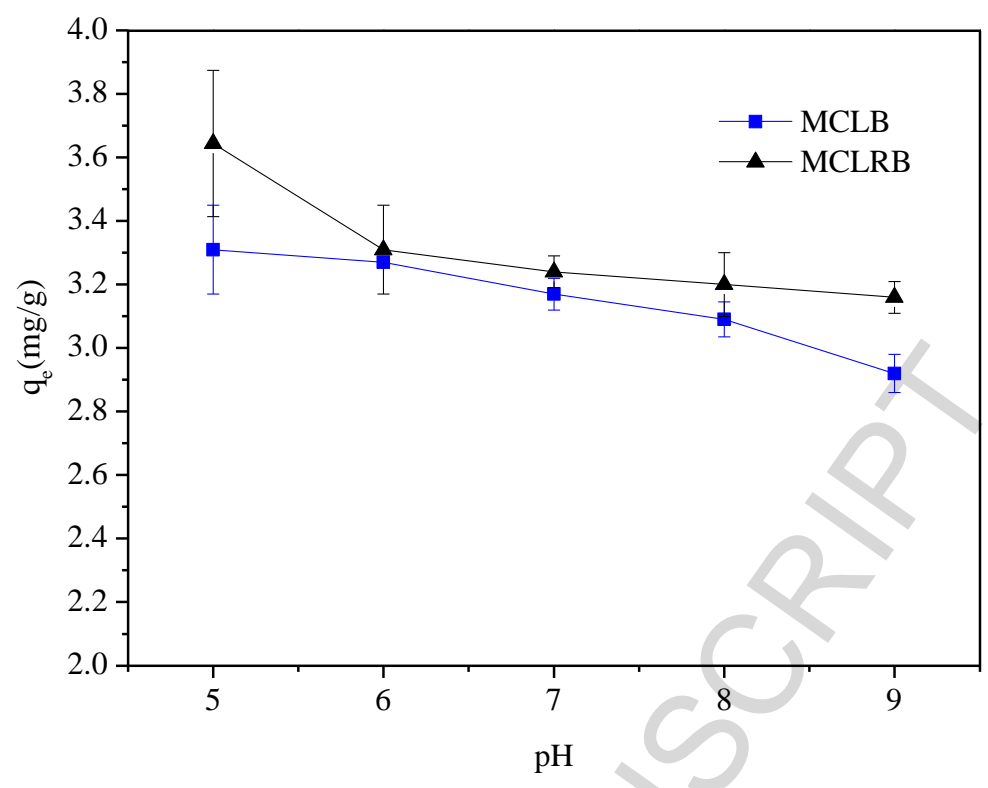


Fig. 7

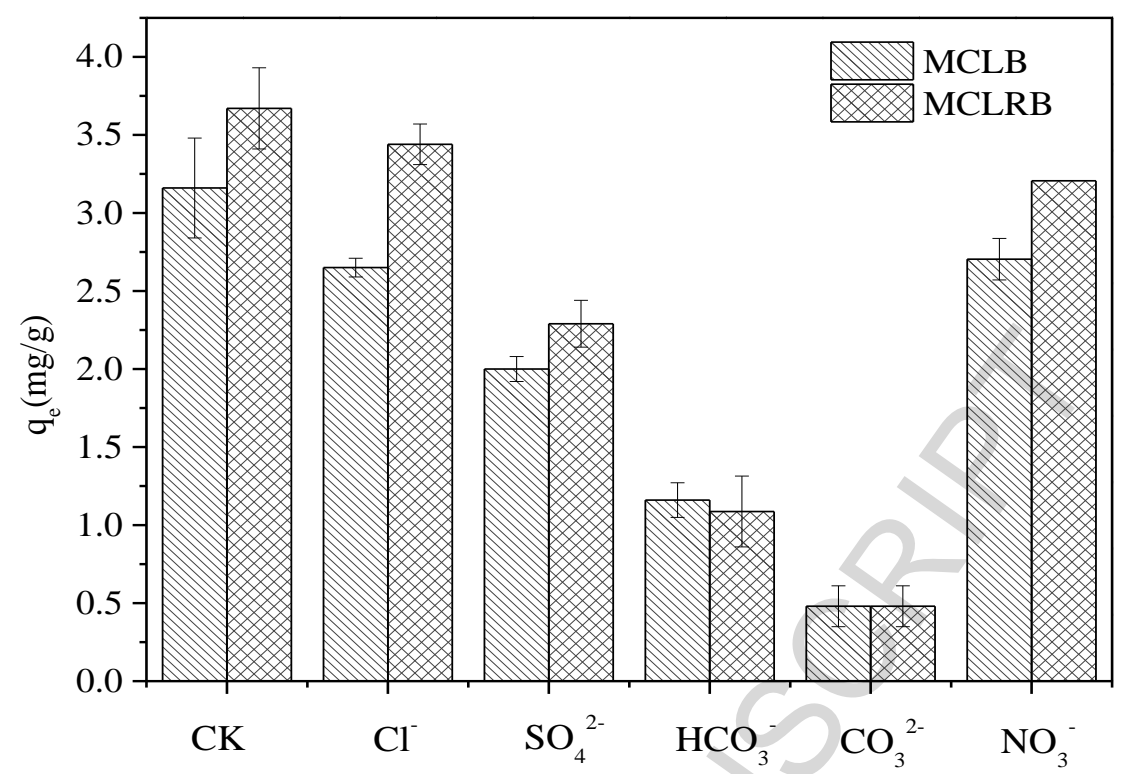


Fig. 8

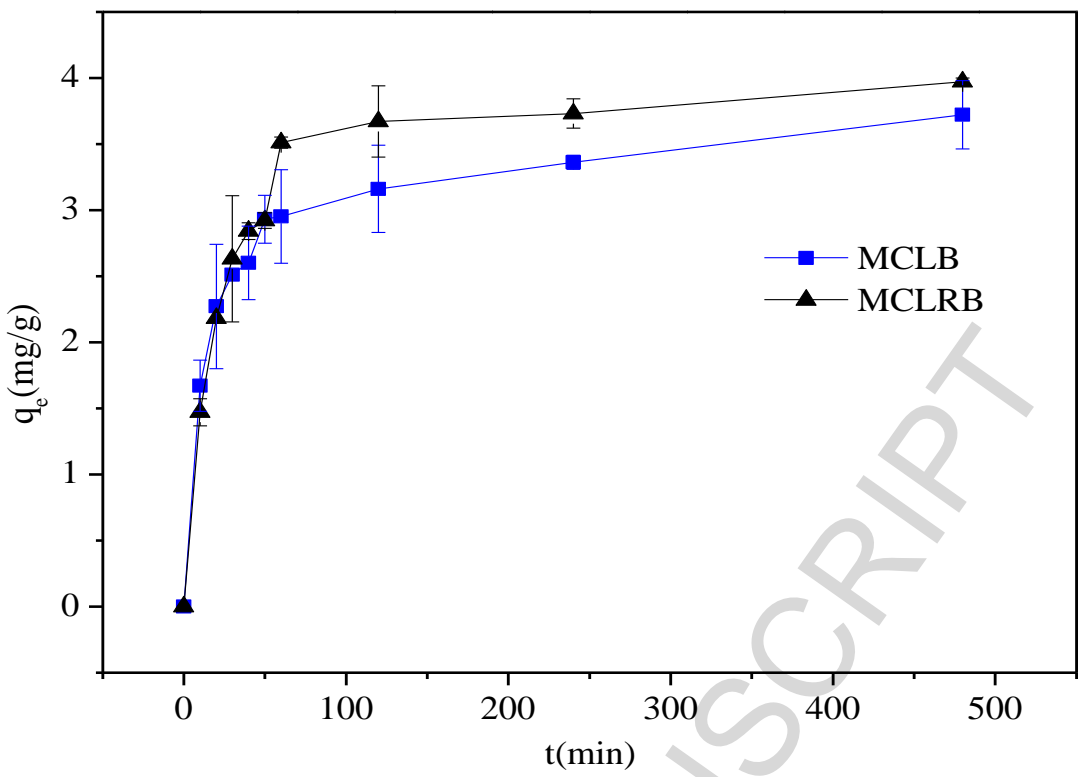


Fig. 9

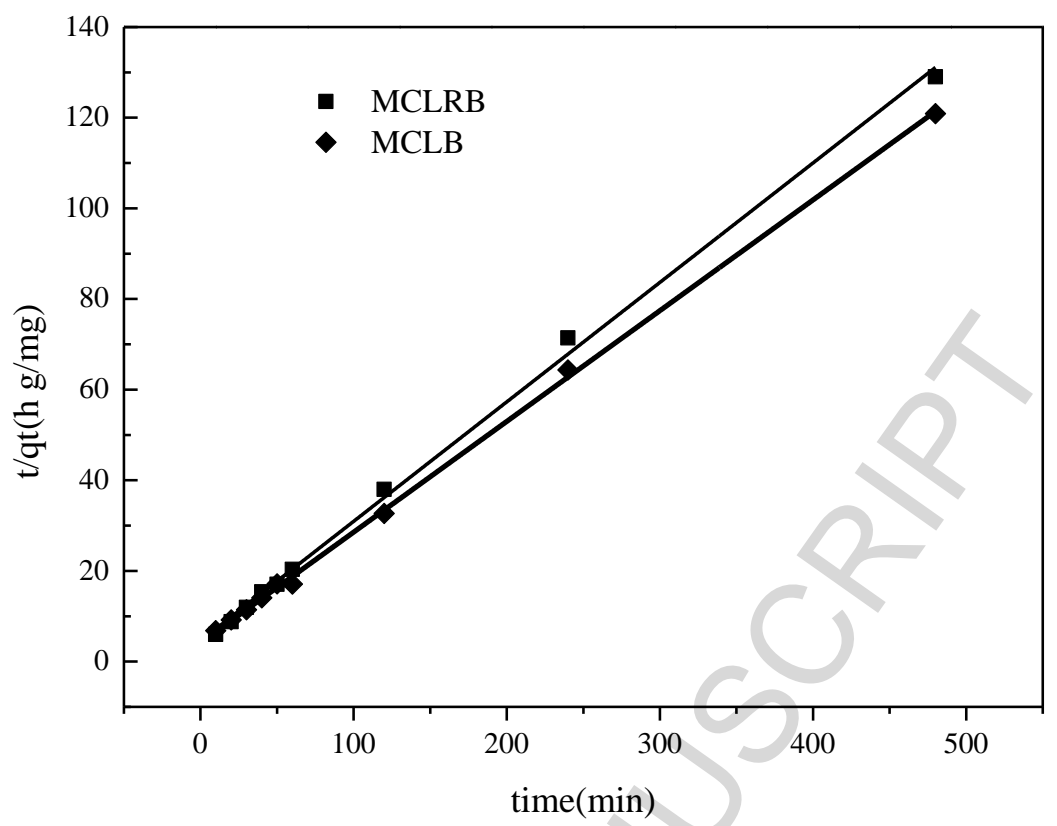


Fig. 10

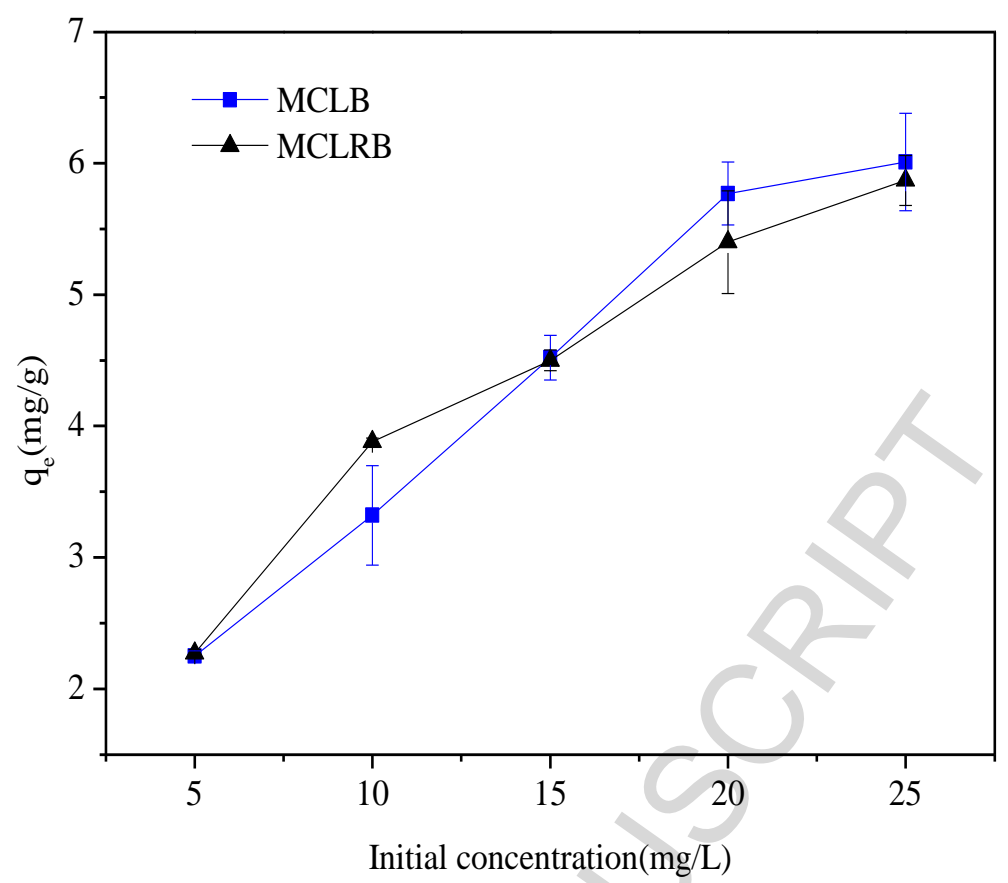


Fig. 11

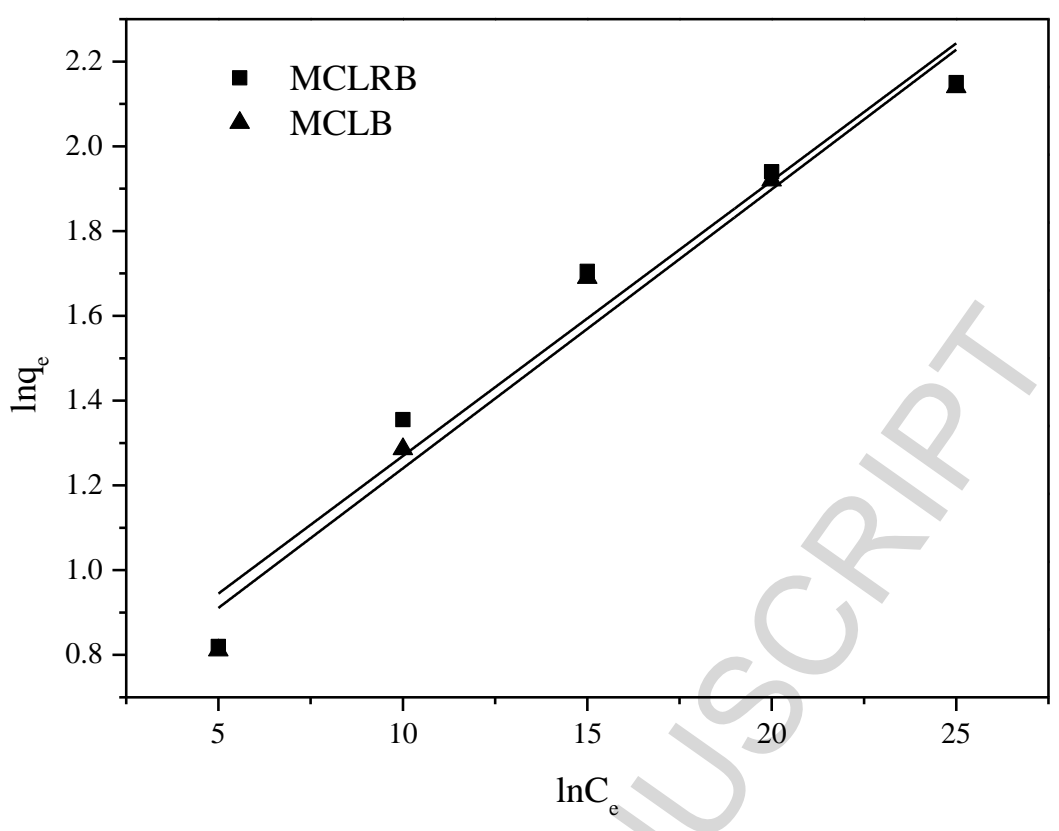


Fig. 12

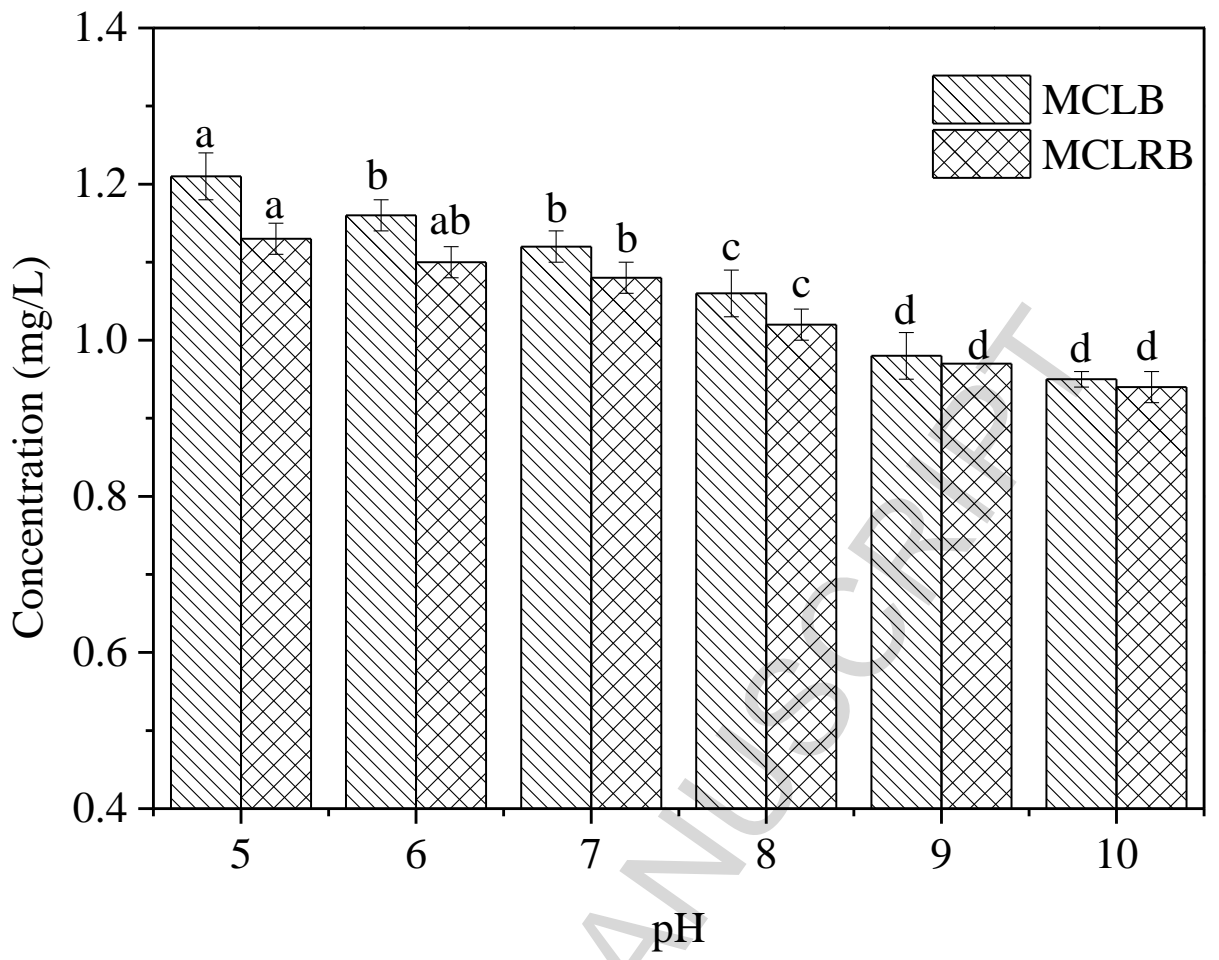


Fig. 13

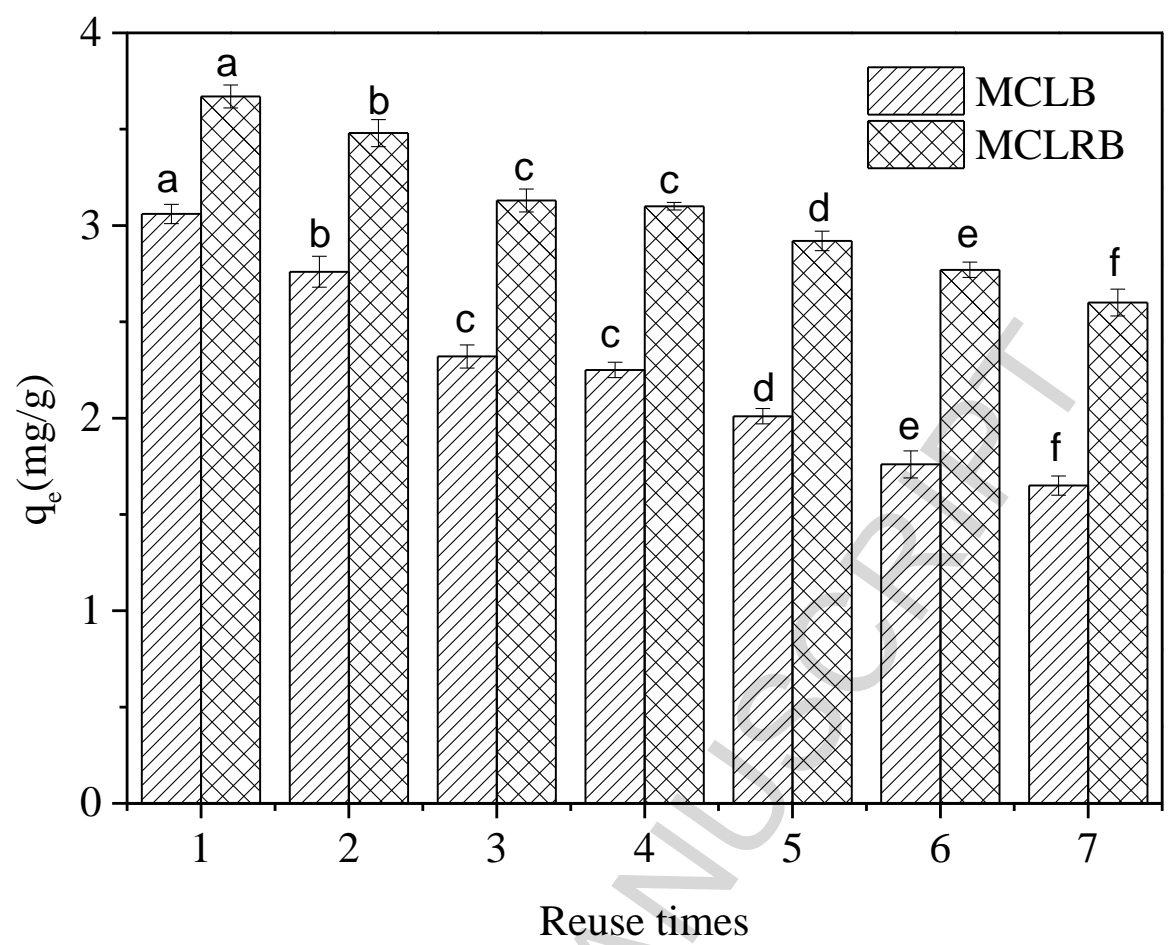


Fig. 14

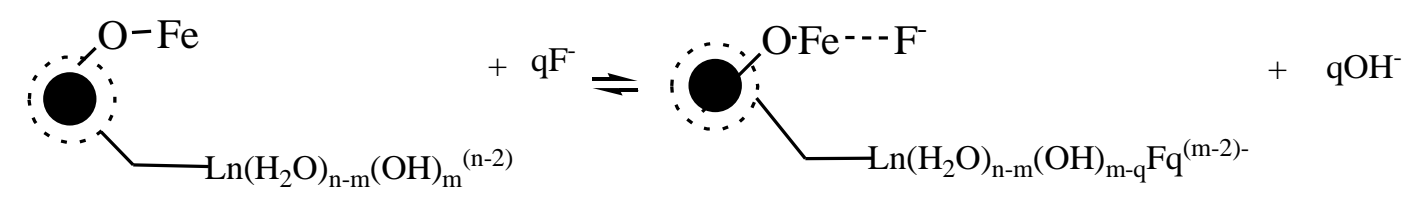

Note: In the schematic description of fluoride adsorption, $\mathrm{O}$ is $\mathrm{Fe}_{3} \mathrm{O}_{4}, \mathbf{C}$ ' is chitosan, and $\mathrm{m}, \mathrm{q}=1$ or 2 . 
Table 1

\begin{tabular}{lll}
\hline adsorbents & BET surface area $\left(\mathrm{m}^{2} / \mathrm{g}\right)$ & average pore diameter $(\mathrm{nm})$ \\
\hline MCLB & 16.64 & 8.15 \\
MCLRB & 21.24 & 7.92 \\
\hline
\end{tabular}


Table 2

\begin{tabular}{|c|c|c|c|c|c|c|c|c|}
\hline \multirow{2}{*}{ adsorbents } & \multicolumn{4}{|l|}{ Pseudo-first-order model } & \multicolumn{4}{|c|}{ Pseudo-second-order model } \\
\hline & Regression equation & $q_{e}(\mathrm{mg} / \mathrm{g})$ & $K_{l}\left(\min ^{-1}\right)$ & $R^{2}$ & Regression equation & $q_{e}(\mathrm{mg} / \mathrm{g})$ & $K_{2}(\mathrm{~g} / \mathrm{mg} \cdot \mathrm{min})$ & $R^{2}$ \\
\hline MCLB & $\log \left(\mathrm{q}_{\mathrm{e}}-\mathrm{q}_{\mathrm{t}}\right)=-0.00639 \mathrm{t}-0.88709$ & 9.1129 & 0.0147 & 0.9489 & $\mathrm{t} / \mathrm{q}_{\mathrm{t}}=0.26361 \mathrm{t}+4.57628$ & 3.7935 & 0.01518 & 0.9979 \\
\hline MCLRB & $\log \left(\mathrm{q}_{\mathrm{e}}-\mathrm{q}_{\mathrm{t}}\right)=-0.00579 \mathrm{t}-0.97601$ & 9.0239 & 0.0174 & 0.8067 & $\mathrm{t} / \mathrm{q}_{\mathrm{t}}=0.24435 \mathrm{t}+4.11757$ & 4.0933 & 0.01494 & 0.9993 \\
\hline
\end{tabular}


Table 3

\begin{tabular}{|c|c|c|c|c|c|c|c|}
\hline \multirow{2}{*}{ adsorbents } & \multicolumn{4}{|c|}{ Langmuir isotherm model } & \multicolumn{3}{|c|}{ Freundlich isotherm model } \\
\hline & $Q_{\max }(\mathrm{mg} / \mathrm{g})$ & $K_{L}(\mathrm{~L} / \mathrm{mg})$ & $R^{2}$ & $R_{L}$ & $K_{F}\left((\mathrm{mg} / \mathrm{g})(\mathrm{mg} / \mathrm{L})^{1 / \mathrm{n}}\right)$ & $n$ & $R^{2}$ \\
\hline MCLB & 20.53 & 0.024 & 0.9832 & 0.625 & & 1.201 & 0.9925 \\
\hline MCLRB & 22.35 & 0.022 & 0.9945 & 0.645 & 2.19 & 1.209 & 0.9985 \\
\hline
\end{tabular}


Table 4

\begin{tabular}{|c|c|c|c|c|}
\hline adsorbents & Temperature (K) & $\Delta G_{0}\left(\mathrm{~kJ} \mathrm{~mol}^{-1}\right)$ & $\Delta H_{0}\left(\mathrm{~kJ} \mathrm{~mol}^{-1}\right)$ & $\Delta S_{0}\left(\mathrm{~kJ} \mathrm{~mol}^{-1} \mathrm{~K}^{-1}\right)$ \\
\hline \multirow{3}{*}{ MCLB } & 303 & -2.13 & 7.89 & -1.32 \\
\hline & 313 & -2.98 & & \\
\hline & 323 & -3.35 & & \\
\hline \multirow{3}{*}{ MCLRB } & 303 & -2.44 & 8.22 & \\
\hline & 313 & -3.13 & & \\
\hline & 323 & -3.78 & & \\
\hline
\end{tabular}

